\title{
Potencial produtivo da cana-de-açúcar sob irrigação por gotejamento em função de variedades e ciclos
}

\author{
Marcelo de A. Silva ${ }^{1}$, Marcel T. Arantes ${ }^{2}$, Andressa F. de L. Rhein ${ }^{3}$, Glauber J. C. Gava ${ }^{4} \&$ Oriel T. Kolln ${ }^{5}$ \\ ${ }^{1}$ FCA/UNESP. Botucatu, SP. E-mail: marcelosilva@fca.unesp.br. Bolsista de Produtividade em Pesquisa (CNPq). (Autor correspondente) \\ ${ }^{2}$ FCA/UNESP. Botucatu, SP. E-mail: marcel_agro@yahoo.com.br \\ ${ }^{3}$ FCA/UNESP. Botucatu, SP. E-mail: andressa_rhein@yahoo.com.br \\ ${ }^{4}$ APTA. Jaú, SP. E-mail: ggava@apta.sp.gov.br \\ ${ }^{5}$ CTBE/CNPEM. Campinas, SP. E-mail: oriel.kolln@bioetanol.org.br
}

\section{Palavras-chave:}

Saccharum spp.

eficiência do uso da água

produtividade

cultivares

pol\% cana

\begin{abstract}
R E S U M O
Este trabalho foi realizado com o objetivo de avaliar o potencial produtivo de diferentes variedades de cana-deaçúcar irrigadas plenamente por gotejamento durante dois ciclos. O experimento foi instalado na região de Jaú, SP, em um Latossolo Vermelho eutrófico. O delineamento experimental foi o de blocos casualizados em arranjo fatorial $8 \times 2$ (variedades $\mathrm{x}$ ciclos), com seis repetições. Em cada ciclo foram avaliadas variáveis de qualidade do caldo, produtividade de açúcar e de colmos e eficiência de utilização de água em relação à produtividade de colmos. Observou-se que variedades de cana-de-açúcar respondem diferentemente à irrigação plena, sendo esta resposta influenciada pelas condições climáticas do ano agrícola. Nesta pesquisa apenas o primeiro ciclo de avaliação (cana-planta) foi determinante para diferenciar o desempenho entre as variedades. As variedades IAC91-1099, IACSP96-3060, RB855536, RB867515 e SP85-1115 apresentaram melhor potencial produtivo agroindustrial e menor consumo relativo de água podendo, então, ser recomendadas para o manejo de produção com irrigação por gotejamento.
\end{abstract}

\section{Key words:}

Saccharum spp.

water use efficiency

productivity

cultivars

pol\% cane

\section{Yield potential of sugarcane under drip irrigation in function of varieties and crop cycles}

\begin{abstract}
A B S T R A C T
This study aimed to evaluate the yield potential of different varieties of sugarcane under drip irrigation in two growth cycles. A trial was set up in October 2006 at Jaú region (São Paulo state, Brazil), in an experimental field with a eutrophic Ultisol. The experiment was conducted in randomized complete blocks with factorial treatment structure $8 \times 2$, constituted by eight sugarcane varieties and two crop cycles, with six replicates. Stalk productivity $(\mathrm{TCH})$, sugar productivity (TPH), juice quality traits and water use efficiency in relation to stalk productivity were evaluated in each crop cycle. It was observed that varieties of sugarcane respond differently to full irrigation, and this response is influenced by climatic conditions of the agricultural year. In this study, only the first evaluation cycle (plant cane) was decisive to differentiate the performance among the varieties. The varieties IAC91-1099, IACSP96-3060, RB855536, RB867515 and SP85-1115 showed higher agro-industrial yield potential and less consumption of water and can be recommended for the management of production under drip irrigation.
\end{abstract}

\section{INTRODUÇÃO}

Entre as grandes culturas, a cana-de-açúcar se destaca como a planta de maior potencial para a produção de massa seca e energia por unidade de área em um único corte por ano. Desde 2006 representa um dos grandes mercados agrícolas brasileiros com previsão de aumento de $40 \%$ na área plantada e da ordem de $100 \%$ na produção, nos próximos 10 anos. A área cultivada, colhida e destinada à atividade sucroalcooleira para a safra 2012/13 estava estimada $8.567,2$ mil hectares, dos quais $51,66 \%$ (4.426,45 mil hectares) seriam produzidos no estado de São Paulo (CONAB, 2012). A produtividade agrícola da cana-de-açúcar também apresentou aumento expressivo no
País decorrente de novas variedades, manejo adequado do solo, uso de resíduos agroindustriais, aplicação racional de adubos e corretivos e expansão da safra (Leite et al., 2011). Entretanto, para manter índices satisfatórios de produção esta cultura necessita de um período quente e úmido, com intensa radiação solar durante o estádio vegetativo seguido de um período seco na fase de maturação e colheita. A qualidade e a intensidade luminosa exercem influência no crescimento vegetativo e na maturação pois estabelecem relação direta com a síntese, translocação e acúmulo de carboidratos das folhas para o colmo. Embora adaptada às condições de elevada intensidade luminosa, altas temperaturas e relativa escassez de água, a cana-de-açúcar necessita de grandes quantidades de água uma vez que somente 
$30 \%$ do peso se constituem de massa seca e os $70 \%$ restantes de água, dependendo do estádio fenológico (Inman-Bamber \& Smith, 2005).

O rendimento e a produção de açúcar e de etanol da canade-açúcar irrigada dependem da quantidade de água aplicada, do manejo de irrigação combinado com a quantidade certa de adubação, da variedade, da idade do corte, do tipo de solo e do clima (Dantas Neto et al., 2006). O fornecimento de matériaprima de qualidade tecnológica a fim de propiciar extração econômica é uma das maiores necessidades da indústria sucroalcooleira (Leite et al., 2011). A carência hídrica da canade-açúcar varia também conforme o estádio vegetativo em que a cultura se encontra e a variedade utilizada sendo, assim, função da área foliar, do estádio fisiológico e da densidade radicular (Dantas Neto et al., 2006).

Os estresses abióticos, como a deficiência hídrica, limitam a produtividade vegetal haja vista serem considerados problemas eminentes para a agricultura e reduzem significativamente os rendimentos das lavouras, além de restringir as latitudes e os solos nos quais espécies comercialmente importantes podem ser cultivadas (Mittler, 2006). Caracteristicamente, a deficiência hídrica não se limita apenas às regiões áridas e semi-áridas do mundo uma vez que mesmo em regiões consideradas climaticamente úmidas a distribuição irregular das chuvas pode, em alguns períodos, limitar o crescimento, restringir o desenvolvimento e prejudicar a produtividade das culturas.

A disponibilidade hídrica do solo é um dos fatores ambientais que mais influenciam a produção da cana-de-açúcar pois determina o estabelecimento da cultura durante o estádio vegetativo (Ramesh, 2000). Comprovadamente, durante o desenvolvimento da cultura a deficiência hídrica promove a restrição dos processos fisiológicos, como divisão e alongamento celular, os quais determinam a redução do acúmulo de massa seca, da taxa de crescimento da cultura e do índice de área foliar (Inman-Bamber \& Smith, 2005).

Praticamente, toda a cana produzida no estado de São Paulo é cultivada em condições de sequeiro cuja tradição é alicerçada no paradigma de que a irrigação de cana-de-açúcar é economicamente inviável nas condições edafoclimáticas do estado de São Paulo. O clima predominante da região de Jaú, SP, é o Aw, de acordo com a classificação de Köppen, caracterizado por uma estação seca definida nos meses de inverno, temperatura média anual de $21,6^{\circ} \mathrm{C}$ e umidade relativa média mensal de $70 \%$, com extremos de $99 \%$, em fevereiro e $19 \%$ em agosto. $\mathrm{O}$ município de Jaú possui média pluviométrica anual de $1.344 \mathrm{~mm}$ e apresenta intensa deficiência hídrica entre abril e setembro, período em que há redução da produção agrícola caso não haja irrigação suplementar.

Segundo Doorenbos \& Kassam (1994), rendimentos de cana-de-açúcar produzida em condições de sequeiro nos trópicos úmidos variam entre $70 \mathrm{a} 100 \mathrm{t} \mathrm{ha}^{-1} \mathrm{e}$, nos trópicos $\mathrm{e}$ subtrópicos secos, com irrigação, rendimentos entre 100 e $150 \mathrm{t}$ $\mathrm{ha}^{-1}$, que podem ser considerados satisfatórios, o que demanda 1.500 a $2.000 \mathrm{~mm}$ por ciclo de 365 dias. Considerando que nas áreas canavieiras do estado de São Paulo a precipitação total anual é em torno de 1.100 a $1.500 \mathrm{~mm}$ anuais, a irrigação complementar se torna indispensável para se obter ganhos em produtividade. Desta forma, durante todo o crescimento a cana-de-açúcar necessita de boas condições de umidade no solo para expressar todo o potencial produtivo; entretanto, o grau de resposta ao ambiente de produção se diferencia conforme as variedades (Silva et al., 2008).

Estudos realizados por vários autores demonstram que os genótipos apresentam resposta diferenciada na produção de biomassa ao aumento do suprimento de água (Evensen et al., 1997; Ramesh \& Mahadevaswamy, 2000; Inman-Bamber \& Smith, 2005). Oliveira et al. (2010) estudaram o crescimento e a produtividade de 11 variedades de cana-de-açúcar sob irrigação plena em Carpina (PE) e observaram maior produção de matéria seca e maior perfilhamento nas variedades RB92579 e SP81-3250 no ciclo de cana-planta.

Considerando que a irrigação é um fator de melhoria do ambiente de produção objetivou-se, com o presente trabalho, avaliar o potencial produtivo de diferentes variedades de canade-açúcar irrigadas por gotejamento durante dois ciclos na região de Jaú, SP.

\section{Material e Métodos}

O experimento foi instalado em outubro de 2006 na Unidade de Pesquisa e Desenvolvimento da Agência Paulista de Tecnologia dos Agronegócios (APTA), Jaú, SP, localizada nas coordenadas $22^{\circ} 15^{\prime} \mathrm{S}$ e $48^{\circ} 34^{\prime} \mathrm{W}$ e em uma altitude média de $580 \mathrm{~m}$. O solo da área foi classificado como Latossolo Vermelho eutrófico típico cujas características químicas analisadas na camada de 0-25 cm apresentaram: $\mathrm{pH}\left(\mathrm{CaCl}_{2}\right) 5,2 ; \mathrm{P}$ (resina) $19,0 \mathrm{mg} \mathrm{dm}^{-3} ; \mathrm{K}-0,9 \mathrm{mmol}_{\mathrm{c}} \mathrm{dm}^{-3} ; \mathrm{Ca}-27,0 \mathrm{mmol}_{\mathrm{c}} \mathrm{dm}^{-3} ; \mathrm{Mg}-4,0$ mmol $\mathrm{dm}^{-3}$; CTC - 105,0 mmol $\mathrm{dm}^{-3} ; \mathrm{V}(\%)$ - 66. E a composição física do solo era de areia $\left(660 \mathrm{~g} \mathrm{~kg}^{-1}\right)$, silte $\left(70 \mathrm{~g} \mathrm{~kg}^{-1}\right)$ e argila $\left(270 \mathrm{~g} \mathrm{~kg}^{-1}\right)$, caracterizando um solo de textura média.

$\mathrm{O}$ ambiente de produção do local foi classificado como $\mathrm{B}_{1}$, cuja característica principal é a média disponibilidade de água com estimativa de produtividade de 92 a 96 t ha $^{-1}$ (Prado, 2005). Com o propósito de elevar a classificação do ambiente para $\mathrm{A}_{1}$, caracterizado pela alta disponibilidade de água e alcançar produtividades acima de $100 \mathrm{t} \mathrm{ha}^{-1}$, foi adotado o manejo de irrigação por gotejamento. As parcelas se constituíram de cinco sulcos duplos de $8 \mathrm{~m}$ de comprimento em um espaçamento de $1,80 \mathrm{~m}$ entre linhas; a cada $0,5 \mathrm{~m}$, no meio da linha dupla e a $20 \mathrm{~cm}$ de profundidade da superfície do solo, foram enterrados tubos gotejadores DRIPNET PC 22135 FL, com vazão de 1,0 $\mathrm{L} \mathrm{h}^{-1}$.

O delineamento experimental utilizado foi o de blocos casualizados em arranjo fatorial $8 \times 2$ (variedades $\mathrm{x}$ ciclos), com seis repetições. As variedades utilizadas foram IAC91-1099, IACSP93-3046, IACSP96-3060, PO88-62, RB855536, RB867515, SP83-2847 e SP85-1115.

Considerada de elevada produtividade agrícola ao longo dos cortes e adaptada à colheita mecânica, a variedade 
IAC91-1099 possui bom teor de sacarose, maturação média, hábito de crescimento ereto, excelente fechamento de entrelinhas e ótima brotação de soqueiras (Landell et al., 2007). A variedade IACSP93-3046, além de apresentar capacidade adequada de brotação em áreas de colheita crua, possui grande estabilidade de produtividade de colmos nos diversos ambientes de produção e época de maturação caracterizada para meio de safra (Landell et al., 2005). A variedade IACSP96-3060 é considerada de alta produtividade agrícola com elevado teor de sacarose; possui maturação, exigência em fertilidade do solo e número de colmos por metros caracteristicamente medianos; não floresce e se apresenta tolerante às principais doenças que acometem a cultura.

A variedade PO88-62 também possui elevados teores de sacarose e produtividade e ainda floresce pouco embora a maturação seja precoce (Caputo et al., 2007; 2008).

Com ampla estabilidade e adaptabilidade aos diversos ambientes de produção, a variedade RB855536 se caracteriza por apresentar hábito de crescimento ereto, maturação média, elevada produtividade agrícola em cana-planta e cana-soca, alto teor de sacarose e excelente brotação de soqueira em colheita crua (UFSCAR, 2008). A variedade RB867515 possui elevada produção agrícola e teor de sacarose, médio período útil de industrialização, brotação adequada na cana-planta e cana-soca, com médio perfilhamento e bom fechamento de entrelinhas. Caracteriza-se, também, pela maturação tardia, reduzida exigência em fertilidade do solo e florescimento acima da média (Simões Neto et al., 2005).

Embora considerada de elevada produtividade mesmo em solos de baixa fertilidade, a variedade SP83-2847 apresenta reduzido teor de sacarose, maturação tardia, acamamento de colmos, médios perfilhamento e florescimento (COPERSUCAR, 1999). A variedade SP85-1115 se destaca pela elevada produtividade agrícola e teor de sacarose, precocidade, desenvolvimento vigoroso e fechamento adequado de entrelinhas. Esta variedade apresenta média exigência em fertilidade do solo, floresce e possui hábito de crescimento caracterizado pelo ligeiro tombamento de colmos (COPERSUCAR, 2003).

Para caracterizar as diferenças entre os dois ciclos de desenvolvimento dessas variedades, o suprimento de água ao solo foi contabilizado pelo somatório do volume de chuva (P) e de irrigação (I). A demanda atmosférica foi calculada pela evapotranspiração da cana-de-açúcar (ET x Kc), com um nível máximo de armazenamento ou capacidade de água disponível (CAD) de $100 \mathrm{~mm}$. Com esses dados foram elaboradas estimativas de balanço hídrico decendial e calculadas as deficiências hídricas (DEF) nos anos agrícolas de 2006-2007 e 2007-2008, empregando-se o método de Penman-Monteith cujos resultados são mostrados na Figura 1.

O primeiro ciclo, com duração de 336 dias, apresentou $1.480 \mathrm{~mm}$ de precipitação total e $400 \mathrm{~mm}$ de água fornecida pela irrigação por gotejamento totalizando $1.880 \mathrm{~mm}$ de água, com evapotranspiração de $1.070 \mathrm{~mm}$ e déficit hídrico

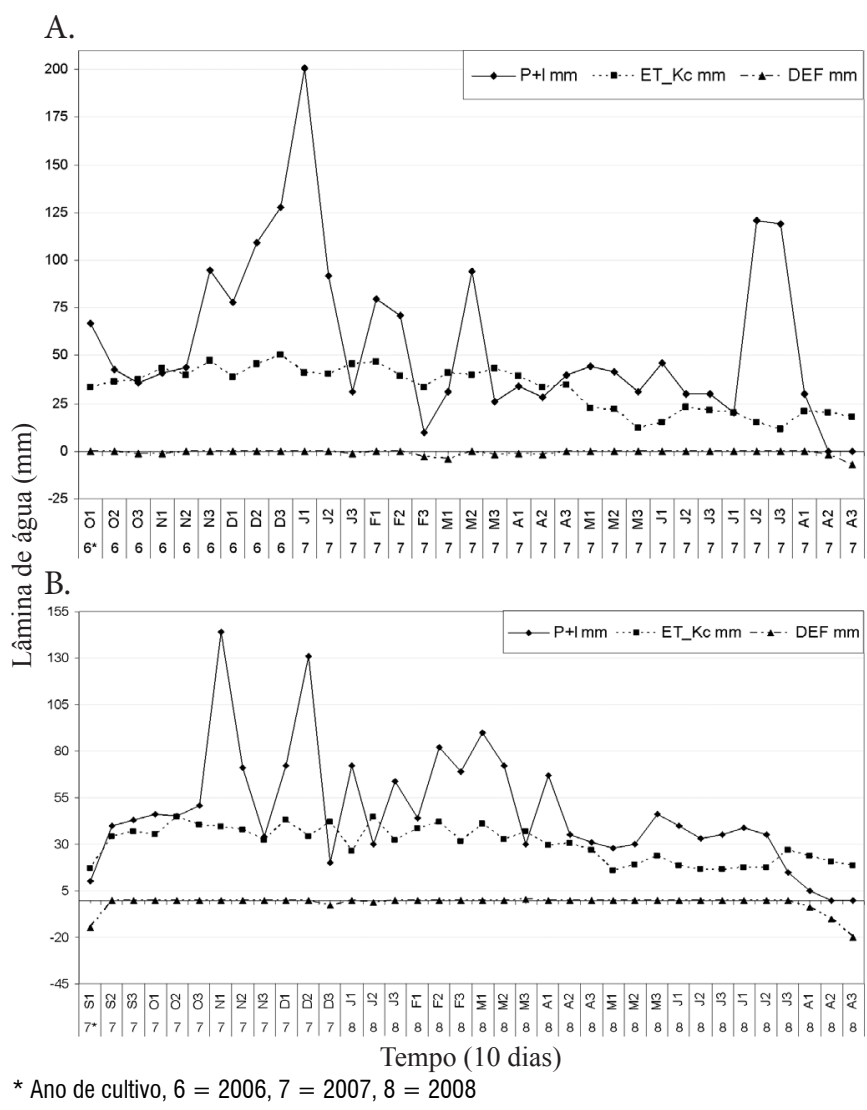

Figura 1. Balanço hídrico em cana-de-açúcar irrigada por gotejamento. A. Primeiro ciclo de crescimento, cana-planta (2006/2007). B. Segundo ciclo de crescimento, cana-soca (2007/2008)

de apenas $24 \mathrm{~mm}$, enquanto o segundo ciclo, com duração de 365 dias, apresentou $1.714 \mathrm{~mm}$ totais de água, com 1.083 $\mathrm{mm}$ evapotranspirados e $38 \mathrm{~mm}$ de deficiência hídrica; trinta dias antes da colheita foi efetuado o corte na irrigação visando favorecer a maturação.

Em todos os tratamentos foram adicionados $180 \mathrm{~kg} \mathrm{P} \mathrm{ha}^{-1}$, na forma de superfosfato simples aplicado no plantio, $220 \mathrm{~kg} \mathrm{~K}_{2} \mathrm{O}$ $\mathrm{ha}^{-1}$, na forma de cloreto de potássio e $150 \mathrm{~kg} \mathrm{~N} \mathrm{ha}^{-1}$, na forma de ureia; no segundo ciclo foram adicionados $150 \mathrm{~kg} \mathrm{~N}^{-1} \mathrm{e}^{130}$ $\mathrm{kg} \mathrm{K}_{2} \mathrm{O} \mathrm{ha}^{-1}$. A aplicação de nitrogênio e potássio foi realizada ao longo do crescimento da cultura por meio de fertirrigação.

Em cada colheita foram coletados e pesados dez colmos nos cinco sulcos duplos de cada parcela. Posteriormente, essas amostras foram encaminhadas ao Laboratório de Tecnologia da Associcana, Jaú, SP, para obtenção dos valores de fibra\% cana (F), Brix (\%), pureza do caldo (PUR), pol\% cana (PCC) e açúcar total recuperável (ATR), de acordo com o método da prensa hidráulica (Fernandes, 2003); em seguida foi obtida a produtividade de colmos em tonelada de cana por hectare (TCH), por meio da relação com a área da parcela. A tonelada de pol por hectare (TPH) foi obtida pelo produto entre a $\mathrm{TCH}$ e a PCC, sendo determinada, também, a eficiência de utilização de água em relação à produtividade de colmos (EUA). A EUA (expressa na forma de consumo em milímetros de água por tonelada de colmo produzida) foi calculada dividindo-se a 
soma da precipitação pluvial efetiva mais a lâmina bruta total de irrigação pela produtividade agrícola (TCH) das variedades. A precipitação pluvial efetiva foi calculada subtraindo-se o excesso hídrico (ocorrido durante o ciclo de produção) da chuva total. Com os dados de $\mathrm{TCH}$ dos primeiro e segundo ciclos foram calculadas as médias de duas colheitas $\left(\mathrm{TCH}_{\mathrm{M}}\right)$ e a produtividade estimada de colmos para cinco colheitas $\left(\mathrm{TCH}_{5}\right)$. Para o cálculo do $\mathrm{TCH}_{5}$ foram usados os dados de TCH de cada colheita os quais foram aplicados na Eq. 1:

$$
\mathrm{TCH}_{5}=\left(\frac{\mathrm{TCH}_{1}+3,5 \times \mathrm{TCH}_{2}}{5}\right)
$$

em que:

$\mathrm{TCH}_{1}$ - valor da produtividade na primeira colheita

$\mathrm{TCH}_{2}$ - valor da produtividade na segunda colheita

Os resultados foram submetidos à análise de variância e as médias comparadas pelo teste de Scott-Knott a 0,05 de probabilidade utilizando-se o programa Sisvar 5.0.

\section{Resultados e Discussão}

Conforme se verifica na análise de variância para características tecnológicas (Tabela 1), os resultados evidenciaram interação significativa $(\mathrm{p}<0,01)$ entre variedades $\mathrm{x}$ ciclos para todas as variáveis. O desdobramento desta interação para Brix, pureza do caldo (PUR) e fibra (F), mostra que apenas o primeiro ciclo de avaliação foi determinante para diferenciar o desempenho entre as variedades (Figuras 2A, 2B e 2C). Tal fato se deve, provavelmente, às maiores oscilações no volume de chuvas ocorridas no ano agrícola de 2006-2007 (Figura 1). As variedades SP89-1115, IACSP96-3060 e IAC911099 se destacaram principalmente no primeiro ciclo, canaplanta, com os maiores valores de Brix e PUR (Figuras 2A e $2 \mathrm{~B}$, respectivamente). Ressalta-se que o valor médio do Brix no primeiro ciclo foi de $18,21 \%$; já no segundo ciclo este valor foi superior para todas as variedades apresentando, em média, $21,74 \%$. Carvalho et al. (2008) encontraram valores médios de Brix de 20,56\% para a variedade SP79-1011 irrigada na terceira soca; este valor é $1,18 \%$ inferior aos encontrados para a cana soca do presente trabalho em regime hídrico de $1.714 \mathrm{~mm}$ totais. Salienta-se que essas variáveis são influenciadas pela variedade,

Tabela 1. Análise de variância das variáveis tecnológicas de oito variedades de cana-de-açúcar irrigadas por gotejamento durante dois ciclos

\begin{tabular}{|c|c|c|c|c|c|c|}
\hline \multirow{2}{*}{$\begin{array}{l}\text { Fonte da } \\
\text { variação }\end{array}$} & \multirow{2}{*}{ G. L. } & \multicolumn{5}{|c|}{ Quadrados médios } \\
\hline & & BRIX & PUR & $F$ & PCC & ATR \\
\hline Variedades (V) & 7 & $1,68^{*}$ & $4,07^{*}$ & $1,11^{*}$ & $1,38^{*}$ & $16,58^{*}$ \\
\hline Ciclos (C) & 1 & $299,70^{* *}$ & $61,49^{* *}$ & $16,70^{* *}$ & $231,14^{\star \star}$ & $20.484,10^{\star *}$ \\
\hline Repetiçõ & 5 & $3,92^{* *}$ & $3,09^{\text {ns }}$ & $1,21^{*}$ & $2,24^{* *}$ & 189 \\
\hline Interação V X C & 7 & $3,24^{* *}$ & $7,11^{* *}$ & $1,97^{\star *}$ & $3,34^{\star *}$ & $282,26^{* *}$ \\
\hline Erro & 75 & 0,68 & 1,73 & 0,46 & 0,57 & 48,33 \\
\hline CV (\%) & & 4,1 & 1,47 & 5,15 & 5,07 & 4,76 \\
\hline
\end{tabular}

C.V.: Coeficiente de Variação; ns: não significativo ( $p>0,05)$; *: significativo $(p<0,05)$; **: significativo $(p<0,01)$

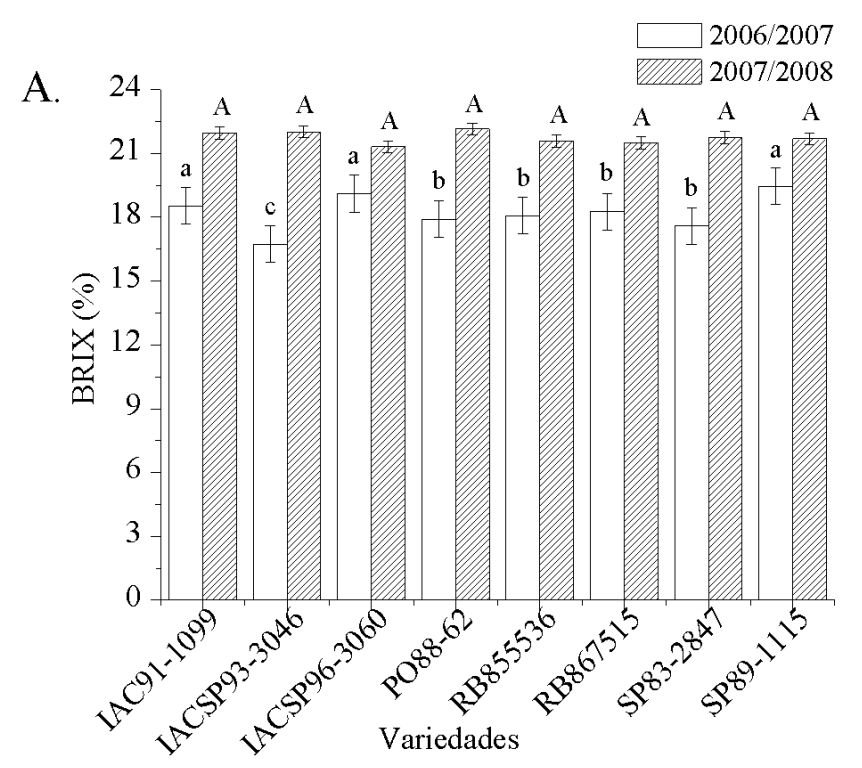

B. 100

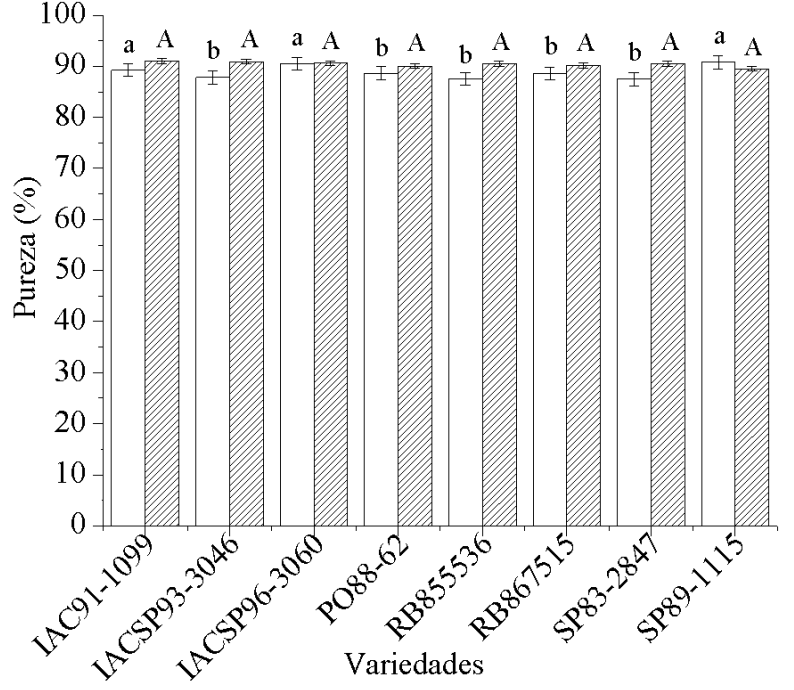

C.
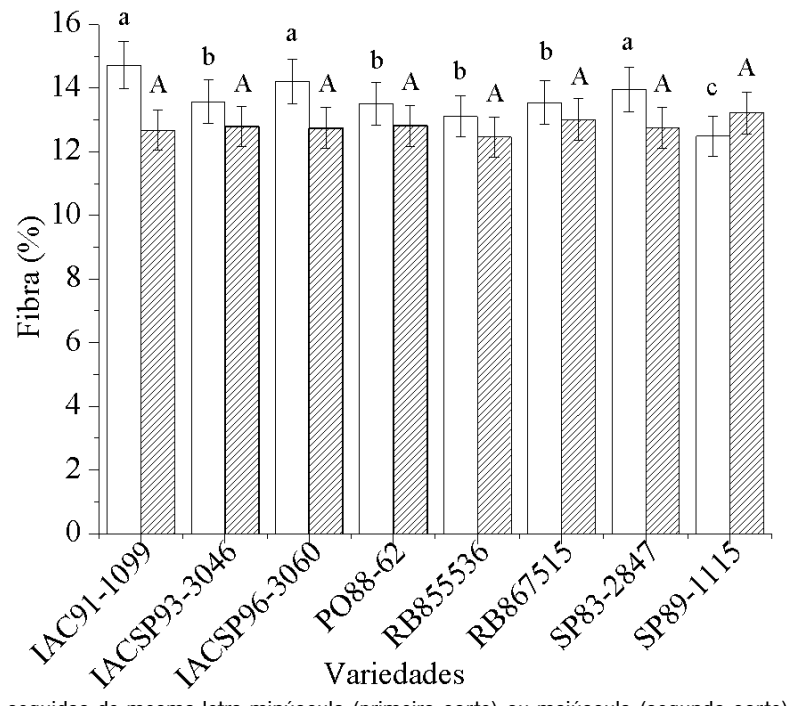

Médias seguidas de mesma letra minúscula (primeiro corte) ou maiúscula (segundo corte) não diferem entre si pelo teste Scott-Knott $(P>0,05)$

Figura 2. Brix do caldo (A), pureza do caldo (B) e fibra da cana (C) dos primeiro (2006/2007) e do segundo (2007/2008) cortes, de oito variedades de cana-deaçúcar em manejo irrigado por gotejamento 
pelo ambiente de produção e sobretudo pela disponibilidade de água visto que o teor de açúcar costuma ser adversamente afetado pelo excesso de umidade no estádio de maturação.

Por outro lado, disponibilidade hídrica plena favorece o desenvolvimento da planta, sobremaneira no estádio de grande crescimento, o que promove melhor aproveitamento da radiação solar e realização da fotossíntese (Inman-Bamber \& Smith, 2005), o que deve ter capacitado as variedades SP891115, IACSP96-3060 e IAC91-1099 para melhor resposta na qualidade do caldo. De fato, o aumento da disponibilidade hídrica favoreceu o acúmulo progressivo de sacarose nas células isodiamétricas do tecido parenquimatoso do colmo, refletido pelo elevado valor de Brix, uma vez que a sacarose é um dos sólidos solúveis do caldo e seu aumento resultou em aumento do Brix do caldo.

Os valores médios de pureza do caldo (PUR), indicador da quantidade de açúcares em relação aos sólidos solúveis do caldo e do estádio de maturação da cana-de-açúcar, foram de 88,8 e $90,4 \%$, no primeiro e no segundo ciclos de avaliação, respectivamente, inferiores aos apresentados pela variedade RB72454 (Dalri et al., 2008); entretanto, próximos aos obtidos pela variedade SP79-1011 (Farias et al., 2009) e superiores aos resultados alcançados por Carvalho et al. (2008), em estudos com esta mesma variedade.

A elevada porcentagem de pureza confirma a alta concentração de sacarose no caldo das variedades, o que reflete em altos rendimentos na indústria proporcionados pela irrigação. Tal fato leva também a melhora da qualidade do caldo devido à redução na quantidade de aminoácidos, ácidos orgânicos, amido, açúcares redutores, além de outros precursores e formadores de cor. No estado de São Paulo os valores mínimos de pureza do caldo devem ser de $80 \%$ (início da safra) ou $85 \%$ (transcorrer da safra) para que seja recomendada a industrialização da cana (Fernandes, 2003). Em todo o Brasil os produtores têm sido remunerados pelos índices qualitativos obtidos na cana-de-açúcar, de modo que o preço pago por tonelada de colmos é diretamente proporcional à qualidade da matéria prima (Farias et al., 2009). Os resultados deste trabalho indicam que a irrigação contribui para elevar a pureza e a qualidade tecnológica da cana-de-açúcar.

Para a porcentagem de fibra (F), as médias foram de 13,6 e 12,8\%, nos primeiro e segundo ciclos de avaliação, respectivamente. As variedades IAC91-1099, IACSP96-3060 e SP83-2847 apresentaram os maiores valores no primeiro ciclo, enquanto no segundo não houve diferença entre as variedades (Figura 2C). Os valores de F obtidos nos dois ciclos de avaliação foram inferiores ao encontrado por Carvalho et al. (2008) em estudo realizado com a variedade SP79-1011 irrigada cujo teor foi $13,91 \%$. Por outro lado, no segundo ciclo de avaliação a irrigação suplementar não alterou a porcentagem de $\mathrm{F}$, em conformidade com estudos realizados na variedade RB72454, que teve valor médio de 10,08\% (Dalri et al., 2008). Entretanto, Oliveira et al. (2011) reportaram que a irrigação plena promoveu redução no teor de fibra médio de 11 variedades proporcionando valor adequado para melhor eficiência da extração do caldo pela indústria.

Portanto, as variedades IAC91-1099 e IACSP96-3060 e SP832847 mantiveram índices satisfatórios de Brix e pureza do caldo, bem como de fibra, o que revela a possibilidade de se tornarem variedades recomendadas para o sistema "cana-energia" sob irrigação por gotejamento, destinada exclusivamente à produção de bioenergia e biomassa, por possuírem crescimento rápido, alto teor de fibras e elevada produtividade (Waclawovsky et al., 2010). Comprovadamente, o teor de fibra na cana-de-açúcar inferior a 10,5\% é indesejável devido ao balanço energético nas usinas e alambiques haja vista ser necessário queimar mais bagaço para manter o poder calorífico nas caldeiras. Desta forma, os teores médios de fibra ideal variam de 10,5 a 12,5\%, valores importantes para a manutenção energética das indústrias que processam a cana-de-açúcar (Fernandes, 2003).

No que se refere à pol\% cana (PCC), porcentagem de sacarose existente na cana (caldo + fibra), e para os açúcares totais recuperáveis (ATR) também se verificou que apenas o primeiro ciclo de avaliação foi determinante para diferenciar o desempenho entre as variedades, das quais SP89-1115 e IACSP96-3060 apresentaram valores de pol\% cana (PCC) acima de $14 \%$ em ambos os períodos de avaliação (Figuras 3A e B, respectivamente).

Para a variedade RB72454 de cana-de-açúcar fertirrigada com nitrogênio e potássio via gotejamento subsuperficial, a PCC foi, em média, 13,57\%, na cana-soca e $14,89 \%$, na ressoca (Dalri \& Cruz, 2008). Em estudos realizados na segunda soca da variedade SP79-1011 de cana-de-açúcar irrigada e sob níveis de adubação de cobertura de 85 e $305 \mathrm{~kg} \mathrm{ha}^{-1}$ da mistura contendo nitrogênio e potássio foram encontrados valores médios da PCC de 13,75 e 13,83\%, respectivamente (Dantas Neto et al., 2006). Contrariamente, Oliveira et al. (2011) observaram menor valor médio de PCC em onze variedades de cana-deaçúcar; entretanto, dentre essas uma apresentou maior valor e outras oito variedades não foram afetadas sob irrigação plena. Segundo Fernandes (2003), no estado de São Paulo, a cana-deaçúcar para ser considerada madura deve apresentar Pol\% cana com variações de 14,4 (início da safra) a 15,3 (transcorrer da safra). Os resultados obtidos neste trabalho revelam a influência positiva da irrigação subsuperficial na qualidade tecnológica das variedades estudadas e corroboram com estudos realizados por Farias et al. (2009).

Os valores de ATR também foram distintos, uma vez que no primeiro ciclo de avaliação, as variedades IACSP96-3060 e SP89-1115 apresentaram ATR de 138,17 e 145,38 $\mathrm{kg} \mathrm{t}^{-1} \mathrm{de}$ colmos, respectivamente (Figura 3B). Referidos valores foram inferiores aos apresentados pela variedade RB72454 irrigada por gotejamento subsuperficial, mas superiores aos obtidos pela mesma variedade fertirrigada com nitrogênio e potássio via gotejamento subsuperficial (Dalri \& Cruz, 2008). Dentre os atributos analisados a variável ATR é fundamental para a indústria e para os produtores haja vista que em função desta variável as unidades industriais elaboram o preço pago aos 
A.

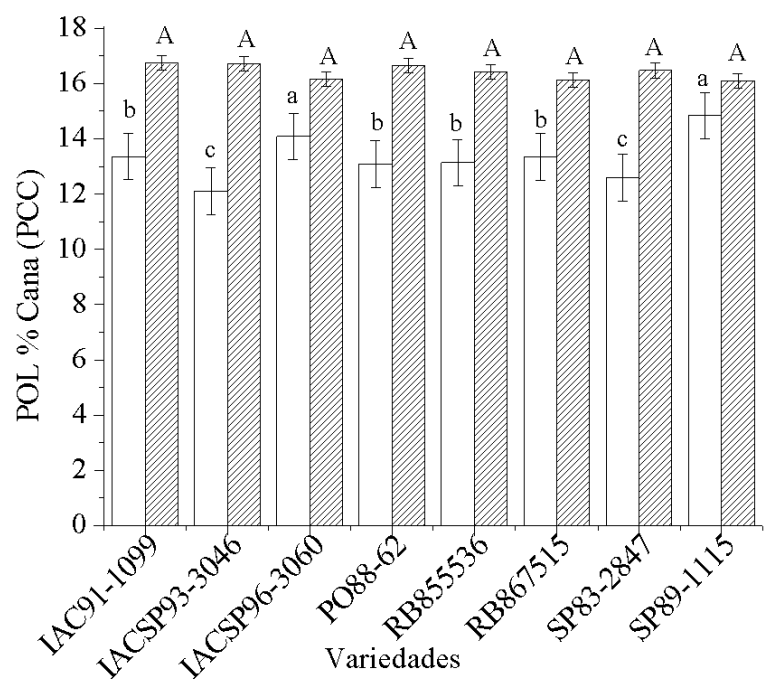

C.

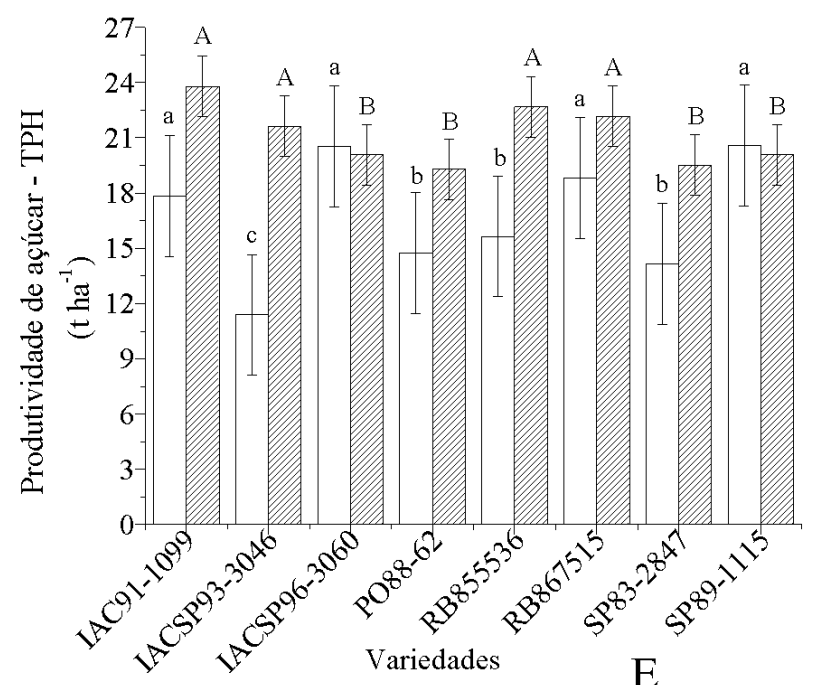

B.

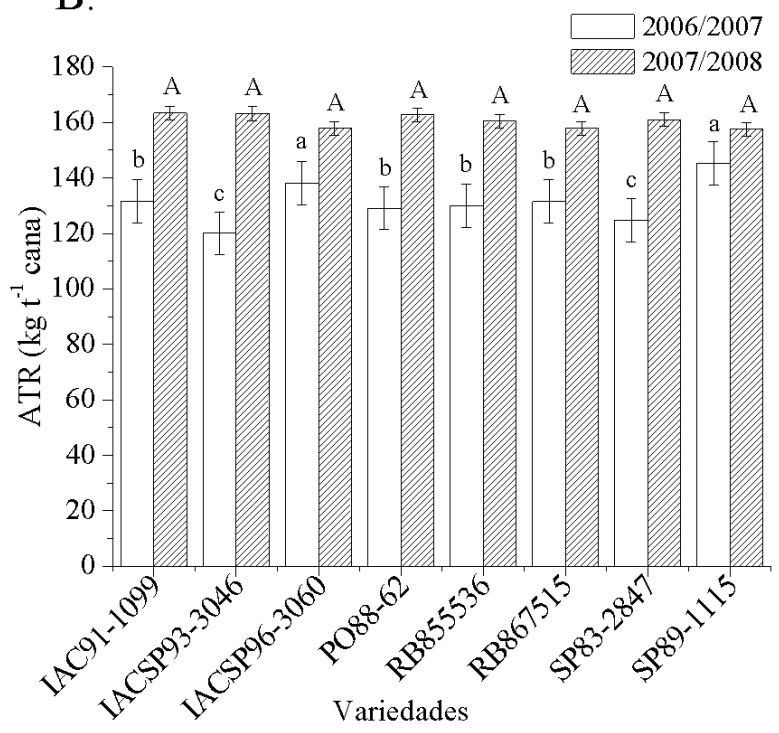

D.

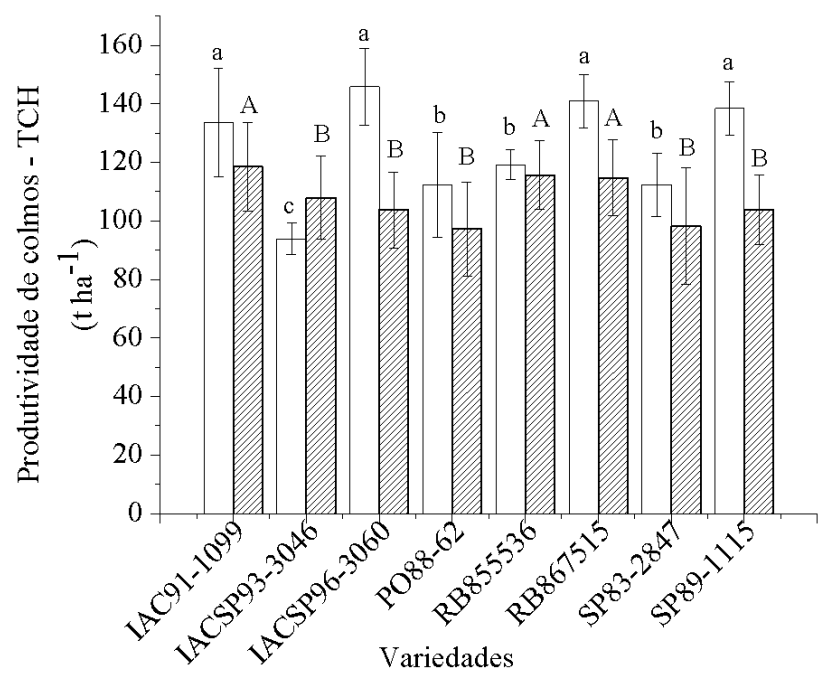

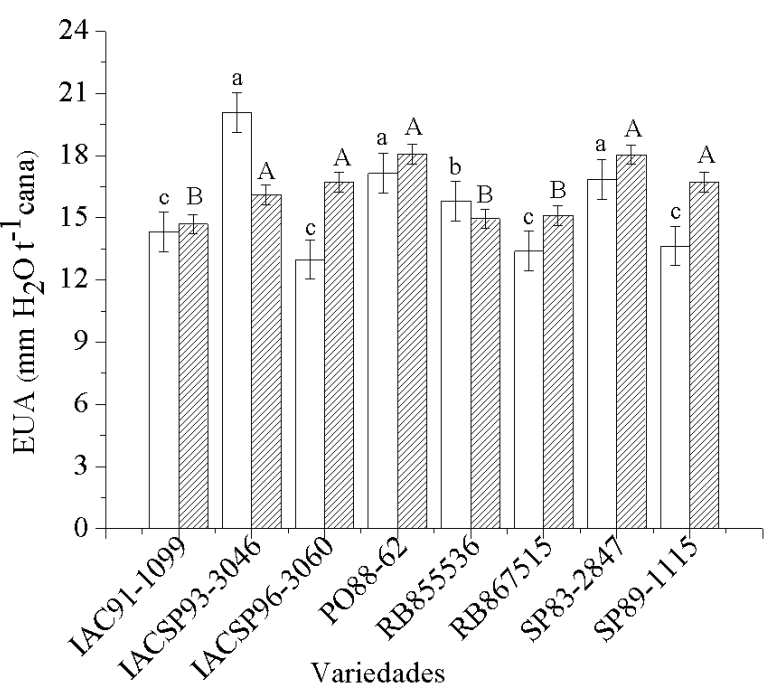

Médias seguidas de mesma letra minúscula (primeiro corte) ou maiúscula (segundo corte) não diferem entre si pelo teste Scott-Knott (P > 0,05)

Figura 3. Porcentagem de sacarose na cana-de-açúcar - PCC (A), açúcares totais recuperáveis - ATR (B), produtividade de açúcar - TPH (C), produtividade de colmos - TCH (D) e eficiência do uso da água - EUA (E) dos primeiro (2006/2007) e segundo (2007/2008) cortes de oito variedades de cana-de-açúcar, sob manejo irrigado por gotejamento 
produtores. Considerando tal aspecto, a qualidade tecnológica dos colmos decorrentes da melhor expressão do atributo ATR é, em parte, devida ao melhor desempenho de algumas variedades à irrigação.

As análises de variância da produtividade de açúcar (TPH), produtividade de colmos (TCH) e da eficiência de utilização de água em relação à produtividade de colmos (EUA) revelaram interação significativa $(p<0,01)$ entre variedades $x$ ciclos (Tabela 2). Esses resultados revelaram que os ciclos de cultivo determinaram diferenças significativas entre as variedades (Figuras 3C, D e E, respectivamente).

Para TPH e TCH, as variedades SP85-1115, IACSP96-3060, RB867515 e IAC91-1099 tiveram as maiores médias no primeiro ciclo, com destaque para IACSP96-3060, com 20,53 $\mathrm{t} \mathrm{ha}^{-1}$ de TPH e 145,81 $\mathrm{t} \mathrm{ha}^{-1}$ de TCH; no segundo ciclo as melhores variedades, tanto para TPH (Figura 3C) quanto para TCH (Figura 3D) foram IAC91-1099, RB855536 e RB867515, com valores acima de $21,5 \mathrm{t} \mathrm{ha}^{-1}$ de TPH e de $115 \mathrm{t} \mathrm{ha}^{-1}$ de TCH. Isoladamente, a variedade IACSP93-3046 teve bom desempenho para TPH e EUA (Figuras 3C e E, respectivamente). Esses resultados mostram distintas respostas varietais à melhoria do ambiente pela irrigação. Tal evidência também foi observada por Oliveira et al. (2010) ao avaliarem a produção de matéria seca de 11 variedades de cana-de-açúcar também sob irrigação plena e além de identificarem diferenças nas respostas devido à distinção genética dos materiais, destacaram a variedade RB92579 como a mais produtiva e reportaram que sua resposta ao incremento hídrico foi decisiva nas fases de perfilhamento e de máximo crescimento quando houve maior aproveitamento da radiação solar. De fato, o perfilhamento é um dos componentes para a formação do potencial de produção da cana-de-açúcar em conjunto com a altura e o diâmetro de colmos (Silva et al., 2008 ; 2010) e a irrigação capacita as variedades responsivas para melhor manifestarem seu potencial genético.

Verificou-se que a EUA variou de acordo com as variedades dentro de cada ciclo de avaliação. Portanto, as diferenças se deram em decorrência da variabilidade genética de cada variedade uma vez que cada ciclo recebeu quantidade semelhante de água (Figura 1). As variedades IACSP93-3046, PO88-62 e SP83-2847 tiveram os maiores valores para EUA no

Tabela 2. Análise de variância de produtividade de sacarose (TPH), produtividade de colmos $(\mathrm{TCH})$ e eficiência do uso da água (EUA) de oito variáveis de cana-de-açúcar irrigadas por gotejamento durante dois ciclos

\begin{tabular}{lcccc}
\hline \multicolumn{1}{c}{ Fonte da } & \multirow{2}{*}{ G. L. } & \multicolumn{3}{c}{ Quadrados médios } \\
\cline { 3 - 5 } variação & 7 & TPH & TCH & EUA \\
Variedades (V) & $70,92^{* *}$ & $1.396,90^{\star *}$ & $4,13^{\star *}$ \\
Ciclos (C) & 1 & $474,15^{* *}$ & $7.024,68^{\star *}$ & $3,05^{\star}$ \\
Repetições (R) & 5 & $22,95^{* *}$ & $379,99^{\text {ns }}$ & $1,28^{\star}$ \\
Interação V x C & 7 & $39,77^{* *}$ & $937,11^{\star *}$ & $2,70^{\star *}$ \\
Erro & 75 & 6,08 & 166,61 & 0,52 \\
CV (\%) & & 13,02 & 11,13 & 11,22 \\
\hline
\end{tabular}

C.V.: Coeficiente de Variação; ns: não significativo $(p>0,05)$; *: significativo $(p<0,05)$; **: significativo $(p<0,01)$ primeiro ciclo (Figura 3E) e no segundo ciclo a IACSP96-3060 incorporou-se a este grupo. Observa-se que essas variedades foram as menos produtivas (Figura 3D) e, portanto, constata-se que a relação entre consumo de água e produtividade é inversa; desta forma, uma variedade será mais eficiente e responsiva quanto maior for sua produtividade e menor o consumo relativo de água. Neste sentido, as variedades IAC91-1099 e RB867515 foram mais responsivas à irrigação plena nos dois ciclos, enquanto IACSP96-3060 e SP89-1115 responderam apenas no primeiro ciclo e a RB855536 apenas no segundo. Diferentes respostas à irrigação em função de variedades também foram verificadas nos estudos realizados por Farias et al. (2008).

Para Doorembos \& Kassam (1994), a eficiência no uso da água na cultura da cana-de-açúcar cultivada nos trópicos e subtrópicos secos, com irrigação, em solos com $80 \%$ de água disponível (ou seja, fração de esgotamento de $20 \%$ ) varia de 5 a $8 \mathrm{~kg} \mathrm{~m}^{-3}$, correspondente ao consumo de 20 a $12,5 \mathrm{~mm} \mathrm{t}^{-1}$. A eficiência no uso da água apresentada pelos citados autores pode ser aplicada para a região de Jaú, Centro-Oeste Paulista, visto que os resultados mostraram médias de 15,5 e 16,3 $\mathrm{mm} \mathrm{t}^{-1}$ cana $\left(6,45\right.$ e $\left.6,13 \mathrm{~kg} \mathrm{~m}^{-3}\right)$, nos primeiro e segundo ciclos, respectivamente.

Nas variáveis $\mathrm{TCH}_{\mathrm{M}}$ e $\mathrm{TCH}_{5}$ as variedades IAC91-1099, IACSP96-3060, RB855536, RB867515 e SP85-1115 (Tabela 3) se destacaram com média de produtividade entre elas de 123,43 para $\mathrm{TCH}_{\mathrm{M}}$ e 105,00 para $\mathrm{TCH}_{5}$, atingindo, portanto, o rendimento entre 100 e $150 \mathrm{tha}^{-1}$ recomendado por Doorenbos \& Kassam (1994) para cana-de-açúcar cultivada sob irrigação nos trópicos úmidos. A variável $\mathrm{TCH}_{5}$ indica potencial de longevidade do canavial sendo uma característica fundamental para a economicidade da cultura por representar maior intervalo de tempo entre o plantio e a renovação da área. De acordo com Silva et al. (2010), um canavial economicamente produtivo deve ser conduzido por no mínimo cinco a seis cortes ou até quando a produtividade média atingir ao redor de $65 \mathrm{t} \mathrm{ha}^{-1}$. Portanto, a irrigação plena proporcionou expectativa de produtividade muito acima do mínimo requerido para renovação da área

Tabela 3. Produtividade média de colmos $\left(\mathrm{TCH}_{\mathrm{M}}\right)$ e estimativa de produção média de cinco cortes $\left(\mathrm{TCH}_{5}\right)$, em toneladas por hectare, de oito variedades de cana-de-açúcar irrigadas por gotejamento durante dois ciclos

\begin{tabular}{lcc}
\hline \multicolumn{1}{c}{ Variedades } & $\mathrm{TCH}_{\mathrm{M}}$ & $\mathrm{TCH}_{5}$ \\
IAC91-1099 & $126,04 \mathrm{a}$ & $109,68 \mathrm{a}$ \\
IACSP93-3046 & $100,92 \mathrm{~b}$ & $94,34 \mathrm{~b}$ \\
IACSP96-3060 & $124,76 \mathrm{a}$ & $101,76 \mathrm{a}$ \\
P088-62 & $104,72 \mathrm{~b}$ & $90,50 \mathrm{~b}$ \\
RB855536 & $117,42 \mathrm{a}$ & $104,78 \mathrm{a}$ \\
RB867515 & $127,86 \mathrm{a}$ & $108,53 \mathrm{a}$ \\
SP83-2847 & $105,30 \mathrm{~b}$ & $91,20 \mathrm{~b}$ \\
SP85-1115 & $121,05 \mathrm{a}$ & $100,27 \mathrm{a}$ \\
QM & $69.845,55^{\star *}$ & $33.629,40^{* \star}$ \\
CV (\%) & 8,15 & 9,09 \\
\hline CV - Coeficiente de variação; QM - Quadrado médio; * : significativo ( $\mathrm{p}<0,05) ;$ **: significativo \\
( $\mathrm{p}<0,01)$. Médias seguidas de mesma letra na vertical (nas variedades) não diferem entre
\end{tabular}
si pelo teste Scott-Knott $(p>0,05)$ 
indicando que essas variedades sob esse manejo poderiam ser indicadas como mais rentáveis por terem redução nos custos de operação de renovação.

\section{Conclusões}

1. Variedades de cana-de-açúcar respondem diferentemente à irrigação plena, resposta influenciada pelo ciclo de cultivo.

2. As variedades IAC91-1099, IACSP96-3060, RB855536, RB867515 e SP85-1115 apresentaram melhor potencial produtivo agroindustrial e menor consumo relativo de água, e podem ser recomendadas para o manejo de produção em irrigação por gotejamento.

\section{Literatura Citada}

Caputo, M. M.; Beauclair, E. G. F.; Silva, M. A.; Piedade, S. M. S. Resposta de genótipos de cana-de-açúcar à aplicação de indutores de maturação. Bragantia, v.67, p.15-23, 2008.

Caputo, M. M.; Silva, M. A.; Beauclair, E. G. F.; Gava, G. J. C. Acúmulo de sacarose, produtividade e florescimento de cana-de-açúcar sob reguladores vegetais. Interciencia, v.32, p.834-840, 2007.

Carvalho, C. M. de; Azevedo, H. M. de; Dantas Neto, J.; Melo, E. P.; Silva, C. T. S.; Gomes Filho, R. R. Resposta dos parâmetros tecnológicos da terceira folha de cana-de-açúcar submetida a diferentes níveis de irrigação. Revista Brasileira de Ciências Agrárias, v.3, p.337-342, 2008.

CONAB - Companhia Nacional de Abastecimento. Acompanhamento de safra brasileira: Cana-de-açúcar. Safra 2012/2013. Primeiro levantamento. Brasília: CONAB, abril/2012. http://www.conab.gov.br/OlalaCMS/uploads/ arquivos/12_04_10_09_19_04_boletim_de _cana.pdf. 2 Mai. 2012.

COPERSUCAR - Cooperativa de Produtores de Cana, Açúcar e Álcool do Estado de São Paulo. 7a. Geração de variedades de cana-de-açúcar. São Paulo: COPERSUCAR. 1999. 32p. Boletim Técnico

COPERSUCAR - Cooperativa de Produtores de Cana, Açúcar e Álcool do Estado de São Paulo. 9a Geração de variedades de cana-de-açúcar. São Paulo: COPERSUCAR. 2003. 16p. (Boletim Técnico).

Dalri, A. B.; Cruz, R. L. Produtividade da cana-de-açúcar fertirrigada com $\mathrm{N}$ e $\mathrm{K}$ via gotejamento subsuperficial. Engenharia Agrícola, v.28, p.516-524, 2008.

Dalri, A. B.; Cruz, R. L.; Garcia, C. J. B.; Duenhas, L. H. Irrigação por gotejamento subsuperficial na produção e qualidade da cana-de-açúcar. Irriga, v.13, p.1-11, 2008.

Dantas Neto, J.; Figueredo, J. L. C.; Farias, C. H. de A.; Azevedo, H. M. de; Azevedo, C. A. V. de. Resposta da cana-de-açúcar, primeira soca, a níveis de irrigação e adubação de cobertura. Revista Brasileira de Engenharia Agrícola e Ambiental, v.10, p.283-288, 2006.
Doorenbos, J.; Kassam, A. H. Efeito da água no rendimento das culturas. Campina Grande: UFPB, 1994. 306p. FAO. Estudos de Irrigação e Drenagem, 33

Evensen, C. I.; Muchow, R. C.; El-Swaify, S. A.; Osgood, R. V. Yield accumulation in irrigated sugarcane: I. Effect of crop age and cultivar. Agronomy Journal, v.89, p.638-646, 1997.

Farias, C. H. A.; Fernandes, P. D.; Dantas Neto, J.; Gheyi, H. R. Eficiência no uso da água na cana-de-açúcar sob diferentes lâminas de irrigação e níveis de zinco no litoral paraibano. Engenharia Agrícola, v.28, p.494-506, 2008.

Farias, C. H. A.; Fernandes, P. D.; Gheyi, H. R.; Dantas Neto, J. Qualidade industrial de cana-de-açúcar sob irrigação e adubação com zinco, em Tabuleiro Costeiro paraibano. Revista Brasileira de Engenharia Agrícola e Ambiental, v.13, p.419-428, 2009.

Fernandes, A. C. Cálculos na Agroindústria da cana de açúcar. 2.ed. Piracicaba: STAB, 2003. 240p.

Inman-Bamber, N.G.; Smith, D.M. Water relations in sugarcane and response to water deficits. Field Crops Research, v.92, p.185-202, 2005.

Landell, M. G. A.; Campana, M. P.; Figueiredo, P.; Vasconcelos, A. C. M.; Xavier, M. A.; Bidoia, M. A. P.; Prado, H.; Silva, M. A.; Miranda, L. L. D.; Santos, A. S.; Perecin, D.; Rossetto, R.; Silva, D. N.; Martins, A. L. M.; Gallo, P. B.; Kanthack, R. A. D.; Cavichioli, J. C.; Veiga Filho, A. A.; Anjos, I. A.; Azania, C. A. M.; Pinto, L. R.; Souza, S. A. C. D. Variedades de cana-de-açúcar para o Centro-Sul do Brasil: $15^{\mathrm{a}}$ liberação do programa cana IAC (1959-2005). Campinas: IAC, 2005. 33p. Série Tecnologia APTA, Boletim técnico IAC, 197

Landell, M. G. A.; Campana, M. P.; Figueiredo, P.; Xavier, M. A.; Vasconcelos, A. C. M.; Bidoia, M. A. P.; Silva, D. N.; Anjos, I. A.; Prado, H.; Pinto, L. R.; Souza, S. A. C. D.; Scarpari, M. S.; Rosa Júnior, V. E.; Miranda, L. L. D.; ; Azania, C. A. M.; Perecin, D.; Rossetto, R.; Silva, M. A.; Martins, A. L. M.; Gallo, P. B.; Kanthack, R. A. D.; Cavichioli, J. C.; Veiga Filho, A. A.; Mendonça, J. R.; Dias, F. L. F.; Garcia, J. C. Variedades de cana-de-açúcar para o Centro-Sul do Brasil: $16^{a}$ liberação do programa cana IAC (1959-2007). Campinas: IAC, 2007. 37p. Série Tecnologia APTA, Boletim técnico IAC, 201

Leite, G. H. P.; Crusciol, C. A. C.; Silva, M. A. Desenvolvimento e produtividade da cana-de-açúcar após aplicação de reguladores vegetais em meio de safra. Semina: Ciências Agrárias, v.32, p.129-138, 2011.

Mittler, R. Abiotic stress, the field environment and stress combination. Trends in Plant Science, v.11, p.15-19, 2006.

Oliveira, E. C. A.; Freire, F. J.; Oliveira, A. C.; Simões Neto, D. E.; Rocha, A. T.; Carvalho, L. A. Produtividade, eficiência de uso da água e qualidade tecnológica de cana-deaçúcar submetida a diferentes regimes hídricos. Pesquisa Agropecuária Brasileira, v.46, p.617-625, 2011.

Oliveira, E. C. A.; Oliveira, R. I.; Andrade, B. M. T.; Freire, F. J.; Lira Júnior, M. A.; Machado, P. R. Crescimento e acúmulo de matéria seca em variedades de cana-de-açúcar cultivadas sob irrigação plena. Revista Brasileira de Engenharia Agrícola e Ambiental, v.14, p.951-960, 2010. 
Prado, H. Ambientes de produção de cana-de-açúcar na região Centro-Sul do Brasil. Piracicaba: Potafos, 2005.p.13-17. Informações Agronômicas, 110

Ramesh, P. Effect of different levels of drought during the formative phase on growth parameters and its relationship with dry matter accumulation in sugarcane. Journal Agronomy and Crop Science, v.185, p.83-89, 2000.

Ramesh, P; Mahadevaswamy, M. Effect of formative phase drought on different classes of shoots, shoot mortality, cane attributes, yield and quality of four sugarcane cultivars. Journal of Agronomy and Crop Science, v.185, p.249-258, 2000.

Silva, M. A.; Cato, S. C.; Costa, A. G. F. Produtividade e qualidade tecnológica da soqueira de cana-de-açúcar submetida à aplicação de biorregulador e fertilizantes líquidos. Ciência Rural, v.40, p.774-780, 2010.
Silva, M. A.; Silva, J. A. G.; Enciso, J.; Sharma, V.; Jifon, J. Yield components as indicators of drought tolerance of sugarcane. Scientia Agricola, v.65, p.620-627, 2008.

Simões Neto, D. E.; Melo, L. J. O. T.; Chaves, A.; Lima, R. O. R. Lançamento de novas variedades RB de cana-deaçúcar. Carpina: UFRPE/RIDESA/EECAC/PMGCA, 2005.28p. Boletim Técnico

UFSCAR - Universidade Federal de São Carlos. Departamento de Biotecnologia Vegetal. Programa de melhoramento genético da cana-de-açúcar. Variedades RB de cana-deaçúcar.1.ed. Araras: CCA/UFSCar, 2008. 30p.

Waclawovsky, A. J.; Sato, P. M.; Lembke, C. G.; Moore, P. H.; Souza, G. M. Sugarcane for bioenergy production: an assessment of yield and regulation of sucrose content. Plant Biotechnology Journal, v.8, p.263-76, 2010. 